\title{
SOME RECENT SURVEYS OF UNEMPLOYMENT
}

\author{
By Royal Meeker, \\ United States Commissioner of Labor Statistics.
}

The fact is that in this country we have a very complete fund of ignorance on the question of unemployment. We have no, or practically no, authentic information as to what the normal amount of unemployment is in this country, even at the best of times. We know that it is immensely great, much greater than there is any excuse for. In foreign countries, the need of accurate information as to the quantity of unemployment is recognized; in this country this is not the case.

A fairly accurate survey was made to determine the extent of unemployment in New York during the winter of 1914-1915, but we haven't anything in previous years to compare with the figures obtained in that survey. We do not know what the unemployment situation was one year ago; we do not know what it was in 1908; we do not know what it was in 1900; we do not know what it was in 1894; we do not know anything accurately about the seasonal fluctuations in employment. We know that unemployment is great in this country, much greater than it should be. Further than that, we cannot go.

I may say that when I took charge of the Bureau of Labor Statistics, I very speedily discovered that so far as the Federal Bureau was concerned, no information existed as to the amount of unemployment or where unemployment existed. Now I conceive that it is the first job of the Federal Commissioner of Labor Statistics to know that very thing. I have been racking my brain trying to devise ways and means by which I can get some line upon the amount of unemployment from month to month in every important city and locality in the United States. As yet I am still racking. I was not able to give the authorities of New York City any information as to the number of the unemployed or the industries that were hardest hit by the depression of last winter, in the early days of the winter when such information would have been most valuable. The Mayor's committee on unemployment in New York made a very accurate estimate of the amount of unemployment in 1914 
as compared with 1913, through the medium of sending out letters of inquiry to employers in the city. I must say that the figures obtained were staggering to me because they seemed to indicate that about 200,000 fewer people were employed in 1914 than in 1913 in the industries in New York City. This is a perfectly staggering amount of unemployment when we consider that 1913 was an abnormal year. That was the year when for the first time unemployment was invented in this country. Up to that time the people of the United States did not recognize that any such thing as unemployment existed. In 1913, for the first time, a meeting, devoted to the subject of unemployment, was held under the auspices of the American Association for Labor Legislation, the first meeting of its kind ever held in this country - the first recognition, even by scientific men, that unemployment does exist, at least at times in this country, and for that reason I say that unemployment was invented in 1913.

Now frankly I did not believe that 200,000 fewer people were employed in New York City in the week ending December 13, 1914, than for the corresponding week one year earlier. The Metropolitan Life Insurance Company took hold of the matter. They conducted an investigation, through their agents, of the holders of industrial life insurance policies in New York City. Their figures seemed, as they came in, to corroborate the figures obtained by the Mayor's committee on unemployment. This seemed to be rather convincing evidence, but it was not convincing enough. No one knows whether the Metropolitan Life Insurance Company, through their industrial policies, give a fair picture of the laboring population of the city of New York; nobody knows whether by taking the industrial policyholders of that city one would get a fair cross section of the city. Only one method of ascertaining unemployment remained untried, namely, the census method. It seemed advisable to employ this means to check up the results obtained by the Mayor's committee and the Metropolitan Life Insurance Company. A complete census of the city was practically impossible. The police were thought of for a while as a medium of making such a census of unemployment, but that scheme was speedily given up.

At first it seemed wholly impracticable for the Bureau of Labor Statistics to make a census of the unemployed in the city of New York, because of the large number of agents necessary to make a canvass sufficiently extensive to represent at all adequately the 
working population of the city. A census of the unemployed by the method of sampling was made possible by the courtesy and coöperation of the Bureau of Immigration and the New York City officials who generously loaned some of their employees to the $\mathrm{Bu}$ reau of Labor Statistics to make the study. I was thus enabled to relieve some of the unemployment. The Immigration Bureau was suffering from the effects of the European war. More than half of the inspectors at Ellis Island were unemployed, and the other half did not have enough to do. I gave them jobs taking the census of the unemployed. The Bureau of Immigration kindly turned over more than fifty of the employees stationed at Ellis Island to me, and I used them in making a census of the city of New York. We did not make a haphazard census; we used brains and the best experience available in mapping out the census. We selected one hundred and four representative city blocks; blocks representing, first of all, the sections inhabited by laboring people. We selected blocks with a view to representing fairly the different industrial elements and the different population elements in the city. In addition to the intensive study carried on by means of the employees of the Immigration Bureau, I used more than one hundred city employees of the tenement department, which the city of New York was kind enough to turn over to me. I set these men at work making a more extensive and intensive investigation. Two dwelling houses-whether tenement houses or private houses, it mattered not-were selected in each of more than 1,700 blocks throughout the whole of Greater New York where laboring people live. In that way we got returns from more than 3,700 houses. The returns from the block census showed a higher percentage of unemployment than was shown in the investigation of selected houses. When we got out into the more suburban and rural districts of New York, we found a smaller percentage of unemployment. We found in some of the crowded downtown blocks of Manhattan Island an appalling percentage of unemployment; in some blocks as high as 40 per cent of the wage-earners were totally unemployed. Farther up the Island we found a smaller percentage of unemployment. I think you will agree with me that it was a perfectly fair census and a perfectly representative cross section of the working classes of New York City.

The investigation proved that about 16.2 per cent of the wageearning population was unemployed. Now nobody knows what 
percentage of the wage-earning population was unemployed in 1913, in 1908, in 1903, in 1900, or in any other year that you may select. We cannot find this out. No one knows how many people were unemployed in 1908, but I suspect about as large a proportion of the working population was idle in that year as during the winter of 1914-15. We do not know-this is simply a supposition.

With our well-nigh inexhaustible resources there should certainly be in this country a lower percentage of unemployment than in any other country in the world. That this is not the case is because we have allowed the industrial development of our country to proceed in a haphazard, unintelligent manner. We have not yet recognized the fact that unemployment exists as a regular condition in carrying on many of our industries. It is absolutely inexcusable that, in this country, with practically untouched resources, where the population is relatively scant, we should have a larger percentage of unemployment, in all probability, than exists in Great Britain, Germany, or France, countries with a relatively redundant population, whose resources are either exhausted or on the way to exhaustion. In this country unemployment should be reduced to the irreducible minimum.

The Bureau of Labor Statistics has published elaborate statistics concerning rates of wages and hours of work, but it has published almost nothing regarding the amount of unemployment in the country. Information as to rates of wages and hours of work is very interesting and important, but the fact that bricklayers in New York City are being paid from five dollars to six dollars a day does not pay the grocery bills of those men who do not have employment as bricklayers. The most useful information for the Bureau of Labor Statistics to furnish is how many jobs there are in the United States, or in any particular locality of the United States; how many people there are available for these jobs. Information as to unemployment is of first importance - the rate of wages, the hours and conditions of employment are of next importance.

The Metropolitan Life Insurance Company found from the census of its industrial policyholders that about 18 per cent of the laboring population of New York City was out of work. The result of the study I made showed that there was 16.2 per cent unemployed, not a great discrepancy. This slight difference may be explained in two ways. First, our study was made about one month after the census of the Metropolitan Life Insurance Company. Things 
at that time were on the upward trend, so it was to be expected that our study would show a smaller percentage of unemployment. Second, the population included in the Metropolitan's survey was a somewhat different population from that included in our census. Most of the Metropolitan's policyholders are in the middle class of the laboring population. The Company probably does not insure as large a proportion of highly skilled workers who receive extraordinarily high wages as of workers who receive moderate wages, and it does not include at all those below a certain wage level, those who have no surplus to invest even in industrial insurance. This might account in part for the slight difference of 1.8 points in unemployment. The figures corresponded so closely that I was willing to ask the Metropolitan Life Insurance Company to make investigations in other places. It has undertaken a census of unemployment in fifteen other cities of the country. If we can get reliable data as to unemployment in several cities, we can make comparisons in space, even if we cannot make comparisons in time. This should give us valuable information as to the distribution of unemployment by cities. The figures have been gathered and are being tabulated, and as soon as ready will be given out. ${ }^{1}$ The complete figures will probably not be published until after July 1, the beginning of the next fiscal year, as no funds are available for printing more bulletins.

This is merely the beginning of a work that has never been undertaken before. The only way to handle it properly is for factory owners to coöperate with state departments and commissions of labor and municipal authorities in getting at the amount of unemployment. The problem of unemployment has never been seriously studied in this country. We must study it before we can hope to solve it. We Americans are too prone to solve problems before we really know what we are solving. We do not even have the problem stated in terms of unknown quantities before we begin working at the solution. We shall never come near to a solution of unemployment by this procedure. We must know, with some de-

${ }^{1}$ Since the above address was delivered the data below on unemployment in fifteen cities of the United States have been given to the press by the U.S. Bureau of Labor Statistics. A canvass was made during March and the first part of April, 1915, which followed the same lines as the Metropolitan's study of unemployment in New York City and vicinity. The families holding industrial policies in the Metropolitan Life Insurance Company were visited by agents of that Company, and the number of partly and wholly unemployed was ascertained. The information thus collected is to appear shortly as a bulletin of the Bureau of 
gree of accuracy, how many people are unemployed in the United States and at what occupations they are unemployed, so to say. Otherwise, how are we to know what the demand is for, let us say, carpenters, and the available supply of unemployed carpenters to meet that demand? This kind of information is known to the labor exchanges of Great Britain and Germany, and that is one reason why, with all their handicaps, these countries have much less marked ups and downs in employment than we do. They handle unemployment with intelligence, while we still shut our eyes to facts and go blithely forward to relieve unemployment in each recurring crisis by handing out bread and soup, old clothes and free lodgings. The people must be brought to realize that work is the only sure cure for unemployment.

Labor Statistics. In the following table are given the leading facts thus far tabulated:

\begin{tabular}{|c|c|c|c|c|c|c|}
\hline \multirow{2}{*}{ Cities } & \multirow{2}{*}{$\begin{array}{l}\text { Number of } \\
\text { families } \\
\text { canvassed }\end{array}$} & \multirow{2}{*}{$\begin{array}{l}\text { Number of } \\
\text { wage- } \\
\text { earners } \\
\text { in families }\end{array}$} & \multicolumn{2}{|c|}{ Unemployed } & \multicolumn{2}{|c|}{$\begin{array}{l}\text { Part-time } \\
\text { wage-earners }\end{array}$} \\
\hline & & & Number & Per cent & Number & Per cent \\
\hline 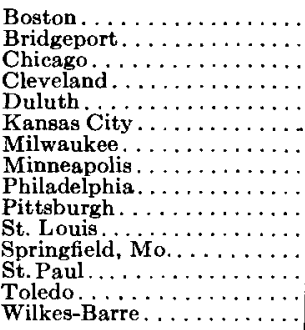 & $\begin{array}{r}46,649 \\
8,144 \\
96,579 \\
16,851 \\
1,383 \\
14,890 \\
8,813 \\
2,206 \\
79,058 \\
36,544 \\
65,979 \\
1,584 \\
2,515 \\
7,233 \\
11,453\end{array}$ & $\begin{array}{r}77,419 \\
12,533 \\
157,616 \\
24,934 \\
2,089 \\
22,512 \\
13,112 \\
3,449 \\
137,244 \\
53,336 \\
104,499 \\
2,284 \\
4,135 \\
10,312 \\
18,884\end{array}$ & $\begin{array}{r}7,863 \\
\mathbf{5 3 7} \\
20,952 \\
2,348 \\
425 \\
2,815 \\
1,030 \\
476 \\
14,147 \\
5,942 \\
14,219 \\
162 \\
582 \\
1,102 \\
1,200\end{array}$ & $\begin{array}{r}10.2 \\
4.3 \\
13.3 \\
9.4 \\
20.3 \\
12.5 \\
7.9 \\
13.8 \\
10.3 \\
11.1 \\
13.6 \\
7.1 \\
14.1 \\
10.7 \\
6.4\end{array}$ & $\begin{array}{r}13,426 \\
2,493 \\
16,575 \\
3,060 \\
371 \\
1,979 \\
3,788 \\
183 \\
26,907 \\
15,474 \\
14,317 \\
32 \\
142 \\
1,801 \\
6,104\end{array}$ & $\begin{array}{r}17.3 \\
19.9 \\
10.5 \\
12.3 \\
17.8 \\
8.8 \\
28.9 \\
5.3 \\
19.6 \\
29.0 \\
13.7 \\
1.4 \\
3.4 \\
17.5 \\
32.3\end{array}$ \\
\hline Total ..... & 399,881 & 644,358 & 73,800 & 11.5 & 106,652 & 16.6 \\
\hline
\end{tabular}

This table relates to part-time workers as well as to the wholly unemployed,

The survey covered 15 cities and included a census of 399,881 families in which were found 644,358 wage-earners. Of this number, 73,800 , or 11.5 per cent, of all wage-earners in the families visited were wholly unemployed, and in addition thereto 106,652 , or 16.6 per cent, were reported as part-time workers. The highest percentage of unemployment was found in Duluth, Minnesota, where 20.3 per cent of the wage-earners were out of work and 17.8 per cent were working part-time only. The lowest percentage of unemployment was found in Bridgeport, Connecticut, where only 4.3 per cent were unemployed, but 19.9 per cent of all wage-workers were reported as working only part-time.

The cities showing the largest percentages of part-time workers were: WilkesBarre, 32.3 per cent; Pittsburgh, 29 per cent; Milwaukee, 28.9 per cent; Bridgeport, 19.9 per cent; Philadelphia, 19.6 per cent; Duluth, 17.8 per cent; Toledo, 17.5 per cent; and Boston, 17.3 per cent. The percentage for all 15 cities combined was 16.6 per cent. 